\title{
Erratum to: Analytical methods for tracing plant hormones
}

\author{
Fuyou Du • Guihua Ruan • Huwei Liu
}

Received: 20 June 2012 / Accepted: 20 June 2012 / Published online: 8 July 2012

(C) Springer-Verlag 2012

\section{Erratum to: Anal Bioanal Chem}

\section{DOI 10.1007/s00216-011-5623-x}

In our original paper the chemical structure of purine of cytokinins in Fig. 1 was incorrect. The authors apologize for any inconvenience this error might have caused. Please find the correct structure of purine of cytokinins below:<smiles>[R17]Nc1ncnc2c1ncn2[R]</smiles>

The online version of the original article can be found at http://dx.doi.org/ 10.1007/s00216-011-5623-x.

F. Du $(\varangle) \cdot G$. Ruan

College of Chemistry and Bioengineering,

Guilin University of Technology,

Guilin 541004, China

e-mail: fydu@glite.edu.cn

H. Liu

Institute of Analytical Chemistry, College of Chemistry and Molecular Engineering, Peking University,

Beijing 100871, China 